\title{
The future of "Retro" robotic partial nephrectomy
}

\author{
David M. Strauss ${ }^{1}$, Randall Lee ${ }^{1}$, Fenizia Maffucci ${ }^{2}$, Daniel Abbott ${ }^{1}$, Selma Masic ${ }^{1}$, Alexander Kutikov ${ }^{1}$ \\ ${ }^{1}$ Division of Urology, Department of Surgery, Fox Chase Cancer Center, Temple University Health System, Philadelphia, PA, USA; ${ }^{2}$ Department of \\ Urology, SUNY Downstate College of Medicine, Brooklyn, NY, USA \\ Contributions: (I) Conception and design: A Kutikov; (II) Administrative support: A Kutikov, Fox Chase Cancer Center; (III) Provision of study \\ materials or patients: All authors; (IV) Collection and assembly of data: All authors; (V) Data analysis and interpretation: All authors; (VI) Manuscript \\ writing: All authors; (VII) Final approval of manuscript: All authors. \\ Correspondence to: David M. Strauss. Division of Urology, Department of Surgery, Fox Chase Cancer Center, Temple University Health System, 333 \\ Cottman Avenue, Philadelphia, PA 19111, USA. Email: David.Strauss2@tuhs.temple.edu.
}

\begin{abstract}
Partial nephrectomy $(\mathrm{PN})$ is the gold standard treatment for appropriately selected renal masses. Recent surgical advancements and adoption of the robotic technique has led to greater adoption of nephron-sparing surgery. Robotic PN was initially described via the transperitoneal (TP) approach, however, retroperitoneal (RP) access is possible and in some cases more desirable. In the RP approach, the kidney is accessed from its posterior surface and the intraperitoneal space is avoided. The RP approach to PN has the benefit of avoiding intraperitoneal viscera and colonic mobilization in patients with extensive prior abdominal surgery. The technique also eliminates the need for renal unit rotation in patients with posterior tumors and affords access to masses directly posterior to the renal hilum. The RP and TP approach to PN have shown similar oncologic and perioperative outcomes. Several recent studies have reported shorter operative times and lengths of stay (LOS) with comparable warm ischemia times for the RP approach when compared to transperitoneal PN (tPN). Given the indispensable deliverables of this approach in select patients, robotic retroperitoneal $\mathrm{PN}(\mathrm{rPN})$ should be in the armamentarium of a versatile urologic kidney surgeon. This review describes the current state of $\mathrm{rPN}$ and compares the indications and outcomes of the TP and RP approaches.
\end{abstract}

Keywords: Retroperitoneoscopic; partial nephrectomy (PN); renal mass; transperitoneal partial nephrectomy; robotic partial nephrectomy

Submitted Sep 16, 2019. Accepted for publication Nov 27, 2019.

doi: $10.21037 /$ tau.2019.12.09

View this article at: http://dx.doi.org/10.21037/tau.2019.12.09

Increasing use of cross-sectional imaging has contributed to the rising incidence of renal cell carcinoma (RCC) and subsequent higher rates of renal surgery. An analysis of Medicare beneficiaries has shown that patients residing in high-scanning regions of the United States are at a higher nephrectomy risk (1). It remains controversial whether the significant increase in early detection and treatment of RCC has led to improved clinical outcomes. Indeed, the potential harm of unnecessary treatment is a significant risk of early cancer detection and must be carefully considered (2). For RCC, treatment paradigms have changed over time, and growing enthusiasm for nephron preservation has resulted in partial nephrectomy (PN) becoming the gold standard approach to the localized renal mass (3).

The surgeon must weigh risks and benefits for PN compared to radical nephrectomy $(\mathrm{RN})$ on a patient to patient basis. These factors are multifactorial and center on potential complications of the surgery, oncologic effectiveness, contralateral renal function and presence of other comorbidities. The theoretical benefit of nephronsparing surgery (NSS) is reduction of future renal function decline in medically complex patients or those at risk for chronic kidney disease (CKD); conversely, NSS carries increased perioperative risks, especially in the setting of a large and complex renal mass (4).

The European Organization for Research and Treatment 
of Cancer (EORTC) trial 30904 highlighted the benefit of kidney functional preservation as well as possible risks for this intervention. EORTC 30904 was a randomized clinical trial that evaluated 273 patients with a unilateral renal mass amenable to $\mathrm{PN}(<5 \mathrm{~cm}$, with normal contralateral kidney) and revealed a lower risk of developing any stage of CKD for patients undergoing $\mathrm{PN}$ as compared to $\mathrm{RN}$ $(64.7 \%$ vs. $85.7 \%, \mathrm{P}<0.001)$ with a 6.7 -year median followup $(5,6)$. With respect to oncologic safety, it was found that there was no difference between $\mathrm{PN}$ and $\mathrm{RN}$ in terms of disease progression ( $4.1 \%$ vs. $3.3 \%, \mathrm{P}=0.48)$ or cancer specific mortality ( $3.0 \%$ vs. $1.5 \%, \mathrm{P}=0.23)$. Additionally, complications for both approaches were reported to compare operative and perioperative safety. The risk of severe hemorrhage was slightly higher after NSS compared to $\mathrm{RN}(3.1 \%$ vs. $1.2 \%)$, and overall reoperation for complications was higher in NSS (4.4\% vs. $2.4 \%)$. This trial showed that the 10-year overall survival was slightly higher for $\mathrm{RN}$ compared to $\mathrm{PN}$ at a median follow-up of 9.3 years, but the finding was not statistically significant $(81.1 \% \mathrm{vs}$. $75.7 \%, \mathrm{P}=0.07)$.

Perioperative and postoperative risks of $\mathrm{PN}$ have been reported by several institutional studies. Tumors with endophytic or hilar anatomy can suggest a more difficult surgical resection and higher risk for perioperative complications such as urine leak or hemorrhage (7). An initial report of laparoscopic PN revealed that the overall complication rate, including urine leak and hemorrhage, was significantly lower for tumors with exophytic or mesophytic masses compared to endophytic or hilar masses $(10.2 \%$, $12.8 \%$ vs. $47.4 \%, 50.0 \% \mathrm{P}<0.001$ respectively). Thus, in addition to patient clinical factors, tumor characteristics must be factored into surgical decision-making when choosing a surgical approach to renal mass. Despite the existing evidence that NSS is the gold standard for localized renal masses amenable to $\mathrm{PN}$, review of practice patterns utilizing the Surveillance, Epidemiology and End Results (SEER) database queried for localized renal masses indicates that NSS remains underutilized (8). This phenomenon is likely secondary to multiple factors which include inequities to access of care and surgeon comfort.

Increased use of NSS and adoption of the robotic platform by the urologic community have led to the robotic approach widely replacing the laparoscopic and open approaches to PN (8). While the initial approach to robotic $\mathrm{PN}$ was described via transperitoneal (TP) access, retroperitoneal $\mathrm{PN}(\mathrm{rPN})$ has since gained traction in many practices (9-22). This manuscript reviews the surgical techniques for $\mathrm{rPN}$, indications and perioperative considerations, current literature, and speculations on future direction and expanding indications of the RP approach.

\section{Surgical technique for rPN}

Starting with positioning, the patient is placed in the lateral decubitus position. The table is flexed to increase the distance between the iliac crest and the subcostal margin. The robot is docked at the head, which requires appropriate coordination with the anesthesia team (Figure 1).

Careful trocar positioning is critical for this procedure. A $12-\mathrm{mm}$ camera port site is marked in the posterior axillary line between the tip of the $12^{\text {th }}$ rib and the iliac crest. A lateral $8-\mathrm{mm}$ port site is marked $6-8 \mathrm{~cm}$ from the $12-\mathrm{mm}$ camera port. Two medial 8 -mm port sites are marked 6-8 $\mathrm{cm}$ from the $12-\mathrm{mm}$ camera port. A $12-\mathrm{mm}$ assist port site is marked just off the iliac crest and triangulated between the $12-\mathrm{mm}$ camera port and the first medial $8-\mathrm{mm}$ robotic port (Figure 2).

A transverse incision for the $12-\mathrm{mm}$ camera port is made with dissection to the lumbodorsal fascia. The RP space is entered bluntly and the RP space is developed with finger dissection. A $12-\mathrm{mm}$ trocar balloon dilator is placed into the developed space and 40 pumps of air are applied to inflate the balloon and further expand the RP space. The lateral 8 -mm port is inserted under direct palpation through the $12-\mathrm{mm}$ camera port. It is extremely helpful to use a long bariatric port in this location, especially when approaching upper pole lesions. The $12-\mathrm{mm}$ camera port is placed (and the internal balloon is inflated), and the camera is introduced. A laparoscopic Kittner through the lateral $8-\mathrm{mm}$ robot port is used to bluntly mobilize peritoneum off the anterior abdominal wall, making room for the two additional $8-\mathrm{mm}$ robotic ports which are then placed under direct visualization. The 12-mm assistant port is placed. The robot is brought into position by docking over the patient's head (Figure 2). The robotic instruments are docked before the camera is docked in order to reduce traction on the camera port and minimize subsequent carbon dioxide leak.

Once the instruments and the camera are docked, Gerota's fascia is identified and incised longitudinally. The hilum is readily identified by medial retraction of the renal unit. Dissection to the renal artery is guided by the psoas muscle. On the left, the dissection proceeds along the psoas, but needs to proceed anterior to the para-aortic lymph 


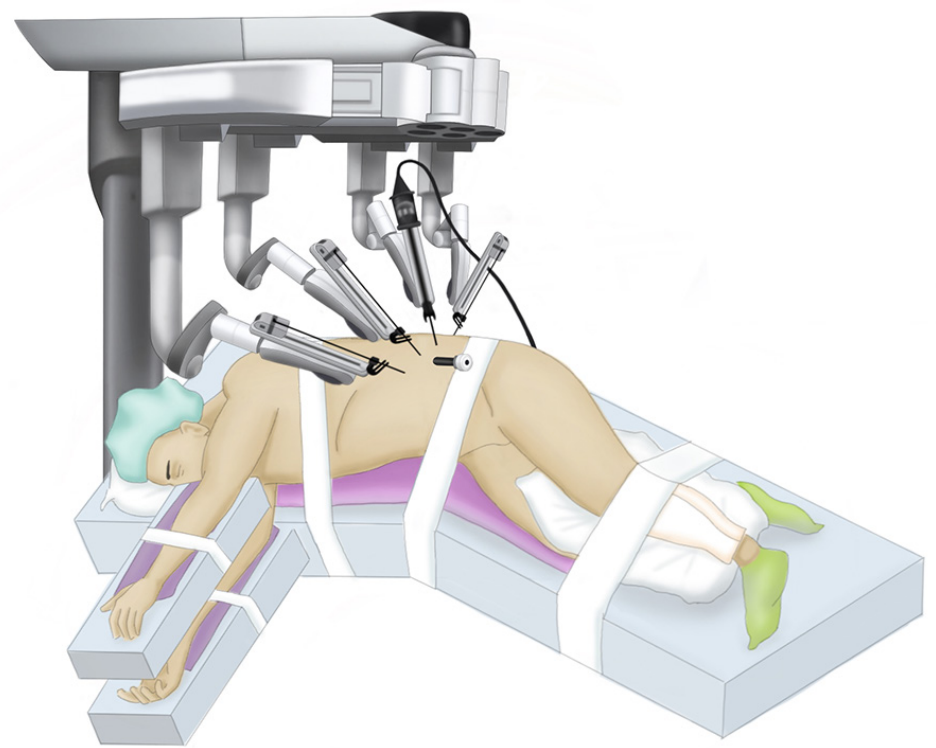

Figure 1 Patient positioning for rPN. Patient is placed in the lateral decubitus position and the OR table is placed in flexion to expand distance between the costal margin and iliac crest. Robot is docked at the patient's head. rPN, retroperitoneal partial nephrectomy; OR, operating room.

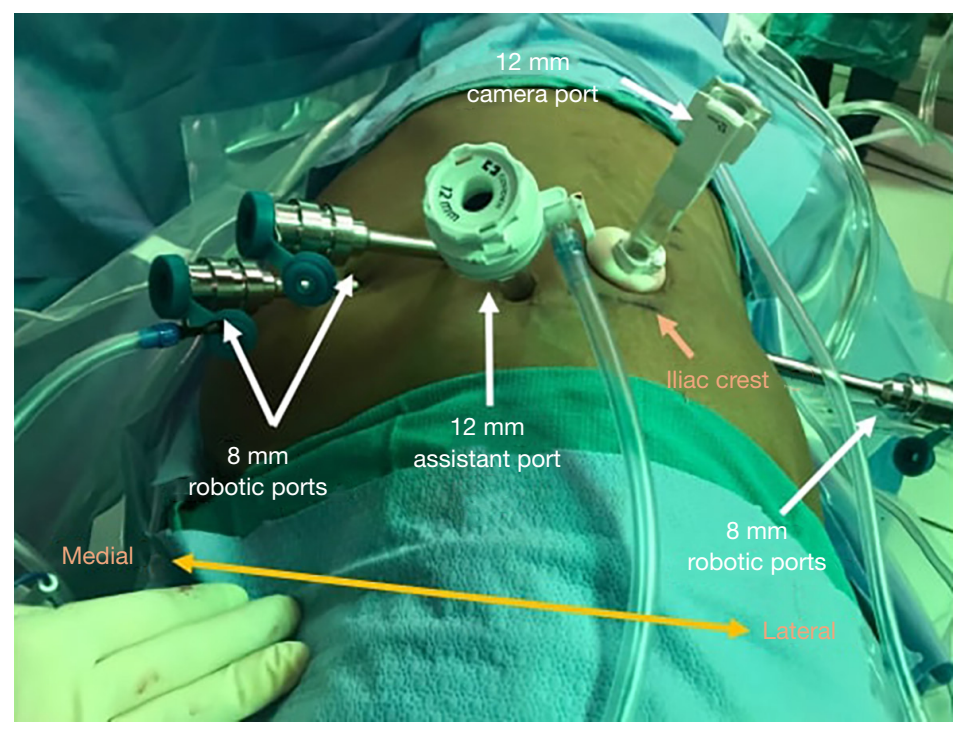

Figure $2 \mathrm{rPN}$ port placement. The iliac crest and costal margin at the 12 th rib are marked. A 12 -mm camera port is placed at the posterior axillary line between the marked anatomic landmarks. Robotic 8-mm ports are placed 6-8 apart, two medial to the camera port and one lateral to the camera port. A $12-\mathrm{mm}$ assistant port is placed just off the iliac crest between the 12-mm camera port and the most medial 8 -mm robotic port. rPN, retroperitoneal partial nephrectomy. 


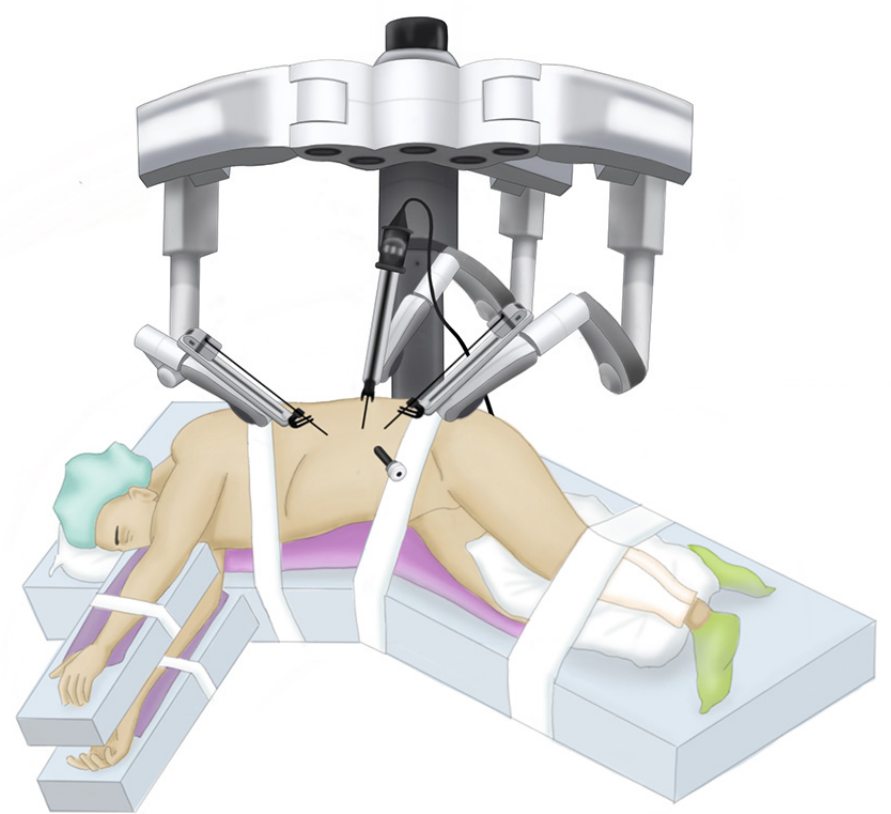

Figure 3 Patient positioning for tPN. Patient is placed in a modified lateral decubitus position. Robot is docked from the patient's side. tPN, transperitoneal partial nephrectomy.

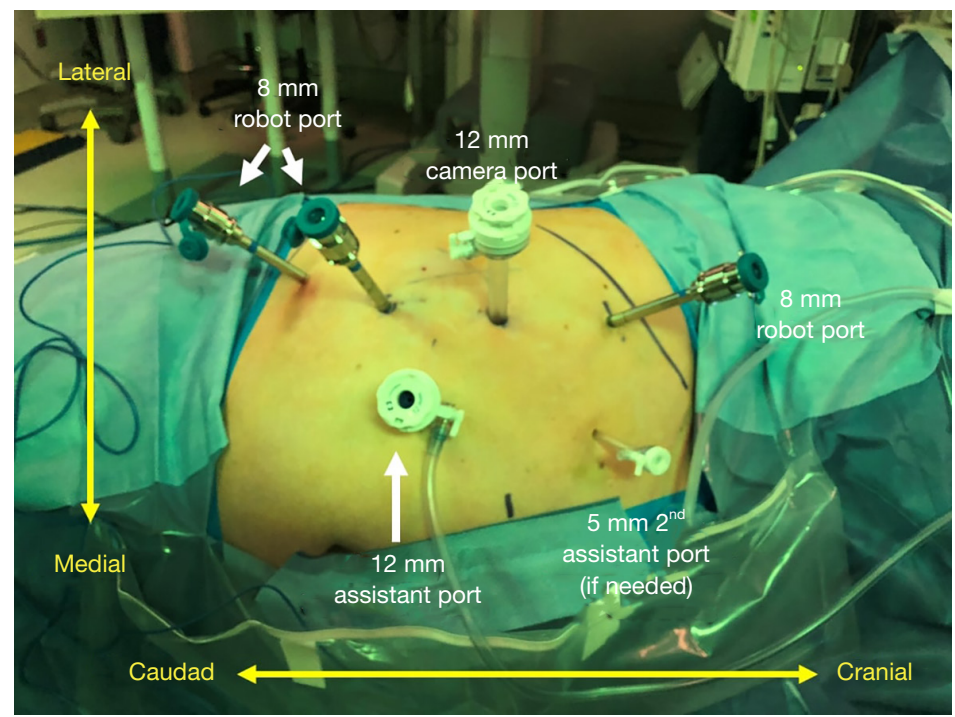

Figure $4 \mathrm{tPN}$ port placement. The costal margin is marked. A 12-mm Camera port is placed cephalad to the umbilicus and lateral to the rectus muscle. The $8-\mathrm{mm}$ robotic ports are placed along a straight line, cephalad to caudad, from the camera port, approximately one hand-breadth apart, starting just underneath the costal margin. A 12-mm assistant port is placed cranial and lateral to the umbilicus. tPN, transperitoneal partial nephrectomy. 

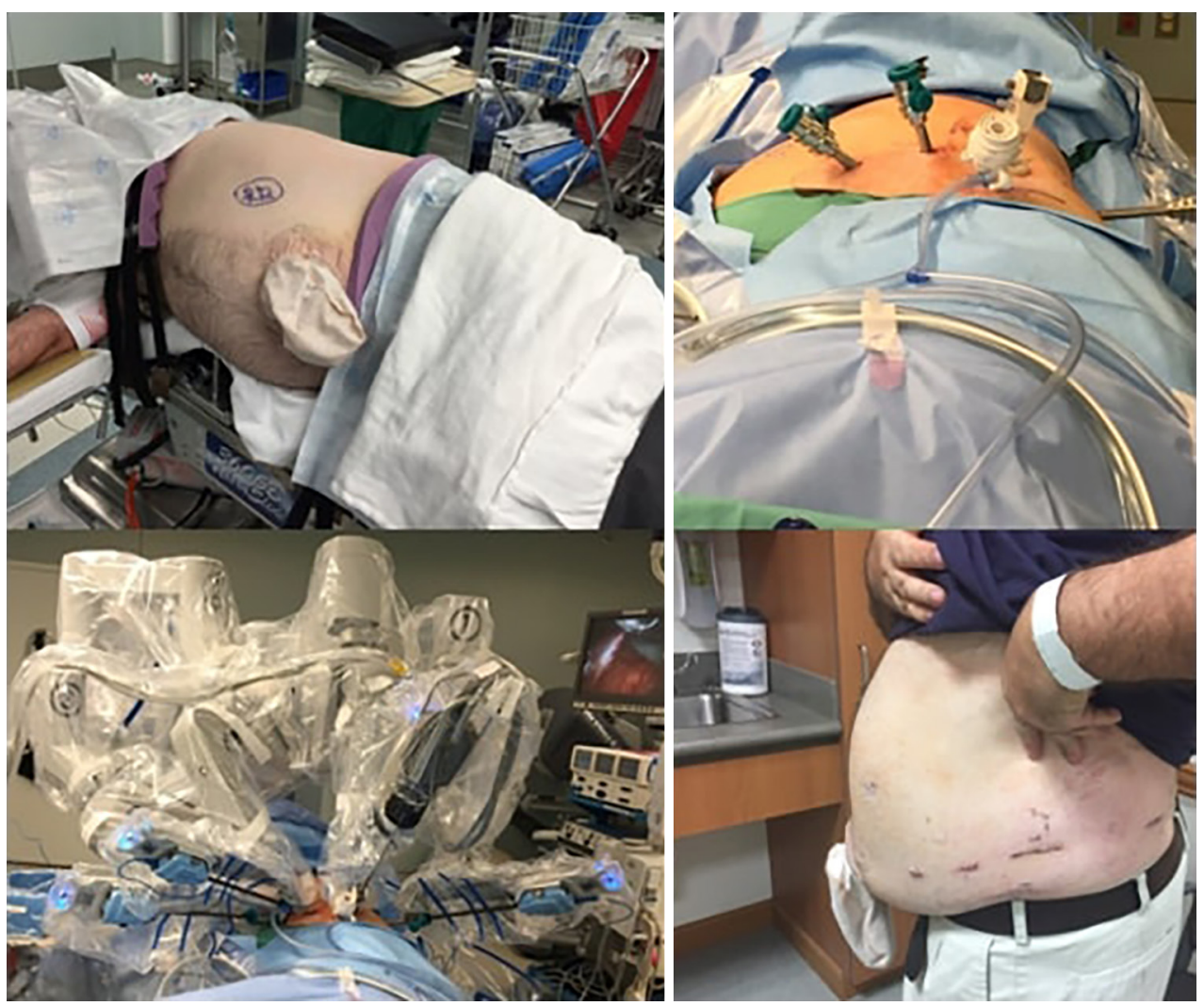

Figure 5 Retroperitoneoscopic robotic partial nephrectomy for a patient with "hostile abdomen". Patient with a colostomy, such as the one pictured, is an appropriate candidate for retroperitoneal access for kidney surgery, as intraabdominal adhesions and pathology are completely avoided.

\section{"The hostile abdomen": patients in whom intraperitoneal dissection must be minimized}

The main benefit of the RP approach is avoiding the intraperitoneal space. This may have significant implications for patients with extensive prior intraabdominal and abdominal wall surgeries, peritoneal dialysis, and medical diseases of the bowel such as inflammatory bowel disease or severe diverticulitis. Avoiding the peritoneal cavity in patients with these conditions reduces the risk of iatrogenic bowel injury at the time of port placement and surgical dissection, and eliminates the time needed for extensive lysis of adhesions (Figure 5).

\section{Tumors on the posterior surface of the kidney}

Another advantage of the RP approach is improved visualization and access to posterior tumors, particularly those immediately behind the renal hilum that can be quite difficult to reach through the TP approach. The RP strategy obviates the need for extensive renal dissection and renal unit rotation, which reduces operative time and risk of injury to the kidney and surrounding structures. Access to the upper pole or more anterior tumors is still possible via $\mathrm{RP}$ access, although it requires more complex dissection and renal mobilization.

While considering the technique, it is important to appreciate the barriers to rPN adoption. There is a steep learning curve for both access and anatomical orientation during rPN. Unfamiliarity with access and anatomical landmarks can lead to risk of vascular injury or prolonged operative times (24). Furthermore, due to a smaller and more restricted working space in the RP, instrument collision can significantly impede surgical progress. Prior $\mathrm{RP}$ access or surgery, including percutaneous nephrostomy 
tubes or nephrolithotomy procedures, can make the RP approach more challenging or impossible (due to inability to safely visualize the great vessels) and should be performed only by experienced providers.

\section{State of the current literature reporting use of rPN}

Experience with the RP approach is growing, and several reports and systematic reviews have compared TP and RP approaches. In a retrospective cohort study, Hughes-Hallett et al. reviewed 103 patients, $44 \mathrm{rPN}$ and $59 \mathrm{tPN}$. They found shorter operative times (148.5 vs. $195.3 \mathrm{~min}, \mathrm{P}<0.01$ ) and lower estimated blood loss (EBL) (88.0 vs. 395.1, $\mathrm{P}<0.01)$ in $\mathrm{rPN}$, without difference in warm ischemia time (WIT) (22.1 vs. 19.1, $\mathrm{P}=0.086)$. The authors concluded that these findings could be explained by less extensive dissection needed for the RP approach, with faster access to the renal hilum and absence of colonic mobilization (17). Similarly, a multicenter study used prospectively maintained databases to retrospectively compare tPN to rPN over 493 cases (99 $\mathrm{rPN}$ and $394 \mathrm{tPN}$ ). At baseline, patients undergoing rPN had smaller tumors ( 2.9 vs. $3.4 \mathrm{~cm}, \mathrm{P}=0.004)$, so stabilized inverse probability of treatment weighting (IPTW) matching was completed to reduce selection bias. In their weighted comparison, the rPN group had lower EBL (100 vs. $125 \mathrm{~mL}, \mathrm{P}=0.007)$ and shorter length of stay (LOS) (1.0 vs. 3.0 days, $\mathrm{P}<0.001$ ) compared to tPN. The authors concluded that the RP approach was not inferior to TP, and can be considered on a patient-by-patient basis (25). Limitations of the two presented studies include absence of matching based on tumor size, location, or complexity which could certainly influence outcomes.

A retrospective propensity-matched study attempted to reduce bias with respect to tumor location and complexity while comparing PN approaches. A multi-institutional collaboration comparing propensity matched (296 TP and $74 \mathrm{RP}$ ) cases of only posterior renal masses from 2007 to 2015, revealed that the RP approach had shorter LOS (2.2 vs. 2.6 days, $\mathrm{P}=0.01$ ), longer WIT (21 vs. $19 \mathrm{~min}$, $\mathrm{P}=0.01$ ), and equivalent $\mathrm{EBL}(150$ vs. $190 \mathrm{~mL}, \mathrm{P}=0.18$ ), overall complications (12.2\% vs. $14.2 \%, \mathrm{P}=0.65)$, operative time (176 vs. $176 \mathrm{~min}, \mathrm{P}=0.93)$, margin positivity ( $1 \%$ vs. $5 \%, \mathrm{P}=1.00)$, and postoperative estimated glomerular filtration rate (eGFR) preservation $(90.4 \%$ vs. $84.9 \%$, $\mathrm{P}=0.25$ ). Patients were matched based on treatment year, age, gender, race, the American Society of Anesthesiologists (ASA) score, body mass index (BMI), and RENAL nephrometry score. The authors fittingly discussed the inherent bias and difficulty of comparing these two approaches, because patient and tumor factors influence surgical approach at the time of patient selection (15).

Another study included 355 patients and compared the two approaches via a 1:1 sub-set propensity matched cohort (78 patients in each arm) based on RENAL nephrometry score, a separate variable of $\mathrm{A} / \mathrm{P} / \mathrm{L}$ status of tumor, and date of surgery (to account for learning curve). Shorter LOS (1.8 vs. 2.7 days, $\mathrm{P}<0.001)$ and shorter operative time $(167$ vs. $191.1 \mathrm{~min}, \mathrm{P}=0.001)$ was noted in the $\mathrm{RP}$ vs. TP group, and no differences were seen in renal function preservation or oncologic control. WIT was similar between tumors of similar RENAL nephrometry score complexity. They acknowledge the low percentage of anterior tumors included in the study, thus raising concerns about the generalizability of the results (26).

A comprehensive synthesis of much of these data is found in a systematic review by Pavan et al, which includes four retrospective studies, the two abovementioned matched pair retrospective studies, and a Japanese prospective non-matched study. In the rPN group, lower operative time, lower EBL, and shorter LOS were observed, while no differences were found for risk of major or minor complications, positive surgical margins or WIT. The authors endorse that the RP approach is preferred for posteriorly located tumors as the approach affords lower EBL and shorter operative time and LOS, although the overall clinical impact of these findings may be small as these factors likely do not play a major role in functional recovery, oncologic efficacy, or quality of life endpoints (27).

\section{Expanding indications of rPN and future}

\section{Direction}

rPN has demonstrated significant benefits for select patients, and may have expanding indications in the future as it becomes more widely adopted. With increasing prevalence of $\mathrm{rPN}$ across centers of excellence and smaller community programs, increasing numbers of trainees and surgeons are likely to gain exposure and contribute to its adoption. Furthermore, the technique has the potential for ongoing advancement and growth as robotic technology continues to improve and competitive forces in this space accelerate.

As discussed in this manuscript, limitations in the available literature surrounding rPN abound and include 
lack of prospective and randomized studies, small sample sizes, and limited experience with anterior tumors. Longerterm experience with this technique is likely to result in growing comfort with complex tumor locations and more comprehensive data. While much of the existing literature of robotic rPN highlights experiences of surgeons at high-volume centers, as rPN becomes more prevalent, published studies will reflect a more diverse population of surgeons and patients, and the results will become more generalizable.

New technology is likely to influence the future direction of both $\mathrm{tPN}$ and $\mathrm{rPN}$ techniques over time. More advanced imaging protocols may become integrated into preoperative decision-making or surgical resection. In a recent study, $3 \mathrm{D}$-printed renal cancer models based on preoperative MRI, were created and given to surgeons planning a $\mathrm{PN}$. A change in approach, tPN converted to $\mathrm{rPN}$, was encountered $\sim 30 \%$ of the time. A significant limitation of this study is the small sample size of ten neoplasms from a single institution, but it is certainly a starting point for future work (28). Furthermore, while selective vessel clamping has been studied in tPN with debatable effects on long-term eGFR, its role in the rPN cohort is even less defined (29). Robotic platform improvement is similarly likely to contribute to change. With time, changes in optics, "smart system software", port configuration, instrument design may all lead to more streamlined surgery and potentially improved patient outcomes. The introduction of single port robotics has the potential to open new doors for robotic $\mathrm{rPN}$, although application of this platform is currently in its infancy and requires further safety data. Kaouk et al. has described the single port robotic approach for various urologic procedures, showing that it is a both a feasible and safe platform (30). Single port robotic rPN ( $\mathrm{SPrPN}$ ) has shown a similar safety profile to that of single port robotic tPN in a small cohort of patients, with relatively short follow up time (30-33). No current longterm oncologic control studies have been completed after SPrPN.

As many aspects of healthcare move toward value-based metrics, policy and market influences may additionally begin to dictate approach of PN. For NSS, the most significant variable in overall cost is the LOS (34). At present, the reported mean hospital cost for laparoscopic $v s$. robotic PN are $\$ 29,800$ vs. $\$ 54,600$ (average per case), and the $\mathrm{RP}$ approach is reported to be $\sim 2,000$ less per case than TP $(35,36)$.

In summary, rPN offers an alternative approach to treatment of select renal masses with comparable oncologic and safety outcomes compared to tPN. The clinical settings in which $\mathrm{rPN}$ can be applied are expanding with growing surgeon experience. As rPN becomes more widely adopted across urologic practices and data evaluating this technique mature, it will undoubtedly become part of the surgical armamentarium for more and more urologists caring for patients with kidney cancer.

\section{Acknowledgments}

Funding: None.

\section{Footnote}

Provenance and Peer Review: This article was commissioned by the Guest Editors (Marc C. Smaldone and Jeffrey J. Tomaszewski) for the series "Controversies in Minimally Invasive Urologic Oncology" published in Translational Andrology and Urology. The article has undergone external peer review.

Conflicts of Interest: All authors have completed the ICMJE uniform disclosure form (available at http://dx.doi. org/10.21037/tau.2019.12.09). The series "Controversies in Minimally Invasive Urologic Oncology" was commissioned by the editorial office without any funding or sponsorship. The authors have no other conflicts of interest to declare.

Ethical Statement: The authors are accountable for all aspects of the work in ensuring that questions related to the accuracy or integrity of any part of the work are appropriately investigated and resolved.

Open Access Statement: This is an Open Access article distributed in accordance with the Creative Commons Attribution-NonCommercial-NoDerivs 4.0 International License (CC BY-NC-ND 4.0), which permits the noncommercial replication and distribution of the article with the strict proviso that no changes or edits are made and the original work is properly cited (including links to both the formal publication through the relevant DOI and the license). See: https://creativecommons.org/licenses/by-nc-nd/4.0/.

\section{References}

1. Welch HG, Skinner JS, Schroeck FR, et al. Regional Variation of Computed Tomographic Imaging in the 
United States and the Risk of Nephrectomy. JAMA Intern Med 2018;178:221-7.

2. Smaldone MC, Egleston B, Hollingsworth JM, et al. Understanding Treatment Disconnect and Mortality Trends in Renal Cell Carcinoma Using Tumor Registry Data. Med Care 2017;55:398-404.

3. Campbell S, Uzzo RG, Allaf ME, et al. Renal Mass and Localized Renal Cancer: AUA Guideline. J Urol 2017;198:520-9.

4. Kim SP, Campbell SC, Gill I, et al. Collaborative Review of Risk Benefit Trade-offs Between Partial and Radical Nephrectomy in the Management of Anatomically Complex Renal Masses. Eur Urol 2017;72:64-75.

5. Van Poppel H, Da Pozzo L, Albrecht W, et al. A prospective randomized EORTC intergroup phase 3 study comparing the complications of elective nephron-sparing surgery and radical nephrectomy for low-stage renal cell carcinoma. Eur Urol 2007;51:1606-15.

6. Van Poppel H, Da Pozzo L, Albrecht W, et al. A prospective, randomised EORTC intergroup phase 3 study comparing the oncologic outcome of elective nephronsparing surgery and radical nephrectomy for low-stage renal cell carcinoma. Eur Urol 2011;59:543-52.

7. Venkatesh R, Weld K, Ames CD, et al. Laparoscopic partial nephrectomy for renal masses: effect of tumor location. Urology 2006;67:1169-74; discussion 1174.

8. Smaldone MC, Kutikov A, Egleston B, et al. Assessing performance trends in laparoscopic nephrectomy and nephron-sparing surgery for localized renal tumors. Urology 2012;80:286-91.

9. Scoll BJ, Uzzo RG, Chen DY, et al. Robot-assisted partial nephrectomy: a large single-institutional experience. Urology 2010;75:1328-34.

10. Hu JC, Treat E, Filson CP, et al. Technique and outcomes of robot-assisted retroperitoneoscopic partial nephrectomy: a multicenter study. Eur Urol 2014;66:542-9.

11. Ghani KR, Porter J, Menon M, et al. Robotic retroperitoneal partial nephrectomy: a step-by-step guide. BJU Int 2014;114:311-3.

12. Feliciano, J, Stifelman M. Robotic Retroperitoneal Partial Nephrectomy: A Four-Arm Approach. JSLS 2012;16:208-11.

13. Frank I, Colombo J Jr, Rubinstein M, et al. Laparoscopic partial nephrectomy for centrally located renal tumors. J Urol 2006;175:849-52.

14. Patel M, Porter J. Robotic retroperitoneal partial nephrectomy. World J Urol 2013;31:1377-82.

15. Maurice MJ, Kaouk JH, Ramirez D, et al. Robotic
Partial Nephrectomy for Posterior Tumors Through a Retroperitoneal Approach Offers Decreased Length of Stay Compared with the Transperitoneal Approach: A Propensity-Matched Analysis. J Endourol 2017;31:158-62.

16. Wright JL, Porter JR. Laparoscopic partial nephrectomy: comparison of transperitoneal and retroperitoneal approaches. J Urol 2005;174:841-5.

17. Hughes-Hallett A, Patki P, Patel N, et al. Robot-assisted partial nephrectomy: a comparison of the transperitoneal and retroperitoneal approaches. J Endourol 2013;27:869-74.

18. Kim EH, Larson JA, Potretzke AM, et al. Retroperitoneal Robot-Assisted Partial Nephrectomy for Posterior Renal Masses Is Associated with Earlier Hospital Discharge: A Single-Institution Retrospective Comparison. J Endourol 2015;29:1137-42.

19. Gin GE, Maschino AC, Spaliviero M, et al. Comparison of perioperative outcomes of retroperitoneal and transperitoneal minimally invasive partial nephrectomy after adjusting for tumor complexity. Urology 2014;84:1355-60.

20. Choo SH, Lee SY, Sung HH, et al. Transperitoneal versus retroperitoneal robotic partial nephrectomy: matchedpair comparisons by nephrometry scores. World J Urol 2014;32:1523-9.

21. Weizer AZ, Palella GV, Montgomery JS, et al. Robotassisted retroperitoneal partial nephrectomy: technique and perioperative results. J Endourol 2011;25:553-7.

22. Ng CS, Gill IS, Ramani AP, et al. Transperitoneal versus retroperitoneal laparoscopic partial nephrectomy: patient selection and perioperative outcomes. J Urol 2005;174:846-9.

23. Minervini A, Carini M, Uzzo R, et al. Standardized reporting of resection technique during nephron-sparing surgery: the surface-intermediate-base margin score. Eur Urol 2014;66:803-5.

24. McAllister M, Bhayani S, Ong A, et al. Vena caval transection during retroperitoneoscopic nephrectomy: report of the compilation and review of the literature. J Urol 2004;172:183-5.

25. Arora S, Heulitt G, Menon M, et al. Retroperitoneal vs Transperitoneal Robot-assisted Partial Nephrectomy: Comparison in a Multi-institutional Setting. Urology 2018;120:131-7.

26. Correa AF, Yankey H, Li T, et al. Renal Hilar Lesions: Biological Implications for Complex Partial Nephrectomy. Urology 2019;123:174-80.

27. Pavan N, Derweesh I, Hampton L, et al. Retroperitoneal 
Robotic Partial Nephrectomy: Systematic Review and Cumulative Analysis of Comparative Outcomes. J Endourol 2018;32:591-6.

28. Wake N, Rude T, Kang S, et al. 3D printed renal cancer models derived from MRI data: application in pre-surgical planning. Abdom Radiol (NY) 2017;42:1501-9.

29. Borofsky MS, Gill I, Hemal A, et al. Near-infared fluorescence imaging to facilitate super-selective arterial clamping during zero-ischemia robotic partial nephrectomy. BJU Int 2013;111:604-10.

30. Kaouk JH, Haber GP, Autorino R, et al. A novel robotic system for single-port urologic surgery: first clinical investigation. Eur Urol 2014;66:1033-43.

31. Maurice MJ, Ramierez D, Kaouk J. Robotic Laparoendoscopic Single-site Retroperitoneal Renal Surgery: Initial Investigation of a Purpose-built Singleport surgical system. Eur Urol 2017;71:643-7.

32. Kaouk JH, Goel RK. Single-port laparoscopic and robotic

Cite this article as: Strauss DM, Lee R, Maffucci F, Abbott D, Masic S, Kutikov A. The future of "Retro" robotic partial nephrectomy. Transl Androl Urol 2021;10(5):2199-2208. doi: 10.21037/tau.2019.12.09 partial nephrectomy. Eur Urol 2009;55:1163-9.

33. White WM, Goel RK, Kaouk JH. Single-port laparoscopic retroperitoneal surgery: initial operative experience and comparative outcomes. Urology 2009;73:1279-82.

34. Uzzo RG, Wei JT, Hafez K, et al. Comparison of direct hospital costs and length of stay for radical nephrectomy versus nephron sparing surgery in the management of localized renal cell carcinoma. Urology 1999;54:994-8.

35. Xia Y, Wang G, Fu B, et al. Evaluation of the Clinical Use of Robot Assisted RP Laparoscopy and Preoperative Renal scoring for Nephron Sparing Surgery in Rental Tumor Patients. Indian J Surg 2018;80:252-8.

36. Laviana AA, Tan H, Hu J, et al. Retroperitoneal versus Transperitoneal robotic-assisted laparoscopic partial nephrectomy: a matched-pair, bicenter analysis with cost comparison using time-driven activity-based costing. Curr Opin Urol 2018;28:108-14. 